\title{
Performance Analysis of Spectrum Management Technique by Using Cognitive Radio
}

\author{
Keisuke Sodeyama and Ryuji Kohno \\ Yokohama National University \\ Japan
}

\section{Introduction}

The usage of the radio spectrum and the regulation of radio emissions are coordinated by national regulatory bodies. As part of radio regulation, the radio spectrum is divided into frequency bands, and licenses for the usage of frequency bands are provided to operators, typically for a long time such as one or two decades. With licensed frequency bands, operators have often the exclusive right to use the radio resources of the assigned bands for providing radio services. Depending on the type of radio service and on the efficiency of the radio systems, frequency bands may be used inefficiently.

Therefore, many national regulatory and standards bodies such as the Federal Communications Commission (FCC)[2], IEEE 802.22 WG [3], and the Ministry of Internal Affairs and communications in Japan have paid attention to the dynamic spectrum access (DSA) technology. Using DSA technology, radio systems can dynamically use and release radio spectrum wherever and whenever they are available. Moreover, DSA technology helps to minimize unused radio spectrum band [9]. This technology is also referred to as cognitive radio technology. Cognitive radio is defined as an intelligent wireless communication system, which may be aware of its environment and adapt to statistical variations in the input stimuli [8].

On the other hand, wireless communications systems such as wireless local area network (WLAN) and Bluetooth are becoming pervasive throughout the world. Especially, the main application of WLAN is wireless connection of PC's to a network but even includes such uses as wireless transmission of moving pictures at indoor environment. Thus, WLAN has dramatically grown in popularity. Bluetooth is also a promising wireless interface solution in mobile ubiquitous environments and is expected to predominate among such applications soon. Meanwhile, some new technologies such as ultra wideband (UWB) radio systems have been proposed for short-range wireless applications [7]. They are expected to spread as a complement to developed technologies such as WLAN and Bluetooth or to be merged with such established technologies.

UWB radio may inherently degrade the performance of the primary systems since the radio band of the UWB radio systems overlaps that of primary systems such as worldwide interoperability for microwave access (WiMAX), 4th generation mobile cellular systems (4G) and field pickup unit (FPU). The technical conditions on the usage of UWB radio system were set up by the Ministry of Internal Affairs and Communications on March 2006, in Japan. In the conditions, it is essential for UWB radio to equip interference mitigation technique, detect and avoid (DAA) [11][12]. 
In the environment for the usage of UWB, coexistence of heterogeneous wireless communications systems are enabled by using the concepts and techniques of the cognitive radio. Cognitive radio is a radio system that can sense the surrounding radio wave environment and use the radio resources efficiently by flexible reconfiguration of the system as a function of the environment changes [4].

Although UWB radio systems with DAA are allowed to transmit with power level of -41.3 $\mathrm{dB} / \mathrm{MHz}$, those without DAA technique must limit their emission level by $-70 \mathrm{dBm} / \mathrm{MHz}$, which is lower than the noise level. Therefore, DAA is essential for UWB radio systems in order to allow them to transmit with the maximum allowed power level.

The question that may arise at this point is how to design the MAC layer of cognitive radio systems such as UWB radio with DAA. Therefore, in this paper, this coexistence environment is analyzed by introducing two important benchmarks and the design issue is discussed based on these results. Moreover, we discuss the detection technique of primary system signals for UWB system with DAA and the effect of UWB system performance using DAA.

The rest of this paper is organized as follows. In Section 2, the cognitive radio system design issue is analyzed. The performance analysis of UWB radio system with DAA technique is presented in Section 3. Finally, conclusions are drawn in section 4.

\section{Analysis of cognitive radio system design issue}

\subsection{System model}

\subsubsection{Channel and traffic model}

We omit the effect of channel errors in order to make the analysis tractable. Hence, the channel is either busy or idle. The offered traffic is modelled with two random processes per radio systems [10], offered traffic and departure rate.

\subsubsection{Radio spectrum usage model}

Without loss of generality, radio spectrum usage model having two different radio systems is considered to analyze this coexistence environment. As shown in Fig. 1, radio system A operates on one frequency channel (center frequency $f_{2}$ ) and radio system B operates on three frequency channels (center frequencies $f_{1}, f_{2}, f_{3}$ ).

Radio system A can be considered as an UWB system with DAA technique and radio system B as a primary system. Radio system B access the channel based on the scheduling algorithm such as a time-division multiple access (TDMA). Radio system A can occupy a wideband radio resource if and only if all of the channels of radio system $B$ are idle. Moreover, radio system A can recognize available channels without sensing error and delay.

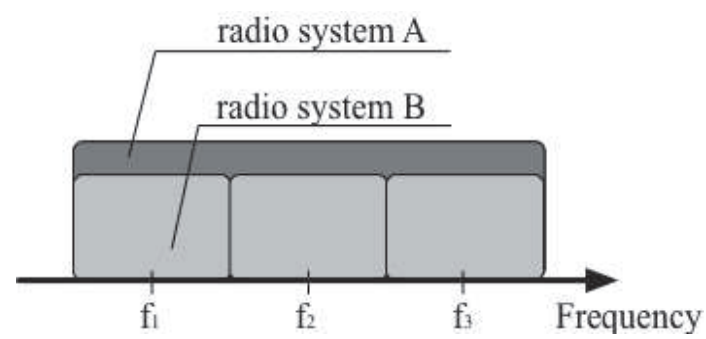

Fig. 1. Frequency channels used by two different types of radio system 


\subsection{Definitions of benchmarks}

In this chapter, we employ "air time" and "interference time" as benchmarks. The "air time" means the ratio of allocation time per radio system to the reference time (say one hour) [10]. Namely,

$$
\text { air time }_{\text {type }}=\frac{1}{N_{\text {type }}} \sum_{i=1}^{N_{\text {type }}} \frac{\text { allocation time }(i)}{\text { reference time }}
$$

where $N_{\text {type }}$ is the number of channels belonging to type $\in A, B$ and allocation time $(i)$ is the total time of radio resources allocated to type. It characterizes the share of resources each radio system can allocate.

The "interference time" refers to the ratio of interfere time to the reference time. Hence,

$$
\text { inerference time }=\frac{1}{N_{B}} \sum_{i=0}^{N_{B}} \frac{\text { inerference time }}{\text { reference time }},
$$

where interference time(i) is the total time when radio system A and B use channels simultaneously. Note that allocation time (i) does not include interference time(i).

The radio systems with different channel bandwidths have different requirements for the throughput performance so that the fairness of the network should be considered. However, the mutual interference of the radio systems is significantly important for the design of this coexistence network compared to throughputs and the fairness since the radio system B is a licensed system, which must be protected from the interference from the radio system A such as the UWB system. Thus, in this paper, the throughput performance is not investigated and our interest is restricted to analyze the mutual influence and the actual channel usage rate.

\subsection{Numerical results}

In this section, computer simulation and the theoretical analysis are presented. We reported the theoretical analysis in [6]. Fig. 2 and Fig. 3 show airtime and interference time versus offered traffic of radio system A or B, respectively. Also, Fig. 4 shows airtime and interference time versus the departure rate of radio system $\mathrm{A}$.

From Fig. 2, interference time is approximately zero over wide range of offered traffic of radio system B because of DAA function of system A. The airtime of system B can achieve about 0.65 without increasing interference time. However, airtime of system $\mathrm{A}$ is decreased by increasing offered traffic of $\mathrm{B}$. Therefore, a trade-off between airtime of system A and that of system B can be found.

From Fig. 3, airtime of system A may be increased by increasing its offered traffic. However, maximal airtime of system A cannot exceed 0.1. On the other hand, offered traffic of system A also increases interference time, of which maximal value is about 0.2 . Therefore, if the system A requires more offered traffic, then that of system A should be increased at the cost of increasing interference time.

From the Fig. 4, while interference time is decreased by increasing the departure rate of radio system A, airtime of radio system B becomes longer. However, airtime of system A is decreased since the occupancy time of channels becomes shorter by increasing the departure rate of system $\mathrm{A}$. 
In order to minimize the interference time, the offered traffic of radio system A should be small and the departure rate large. The airtime of system B is 0.3 and interference time is 0.5 even if offered traffic of system $\mathrm{A}$ is one. On the other hand, the airtime of system B becomes zero and interference time becomes 0.5 if the departure rate of system A is zero. Therefore, the occupancy time of channels should be shortened for system A rather than decreasing offered traffic since the departure rate is inversely proportional to the occupancy time.

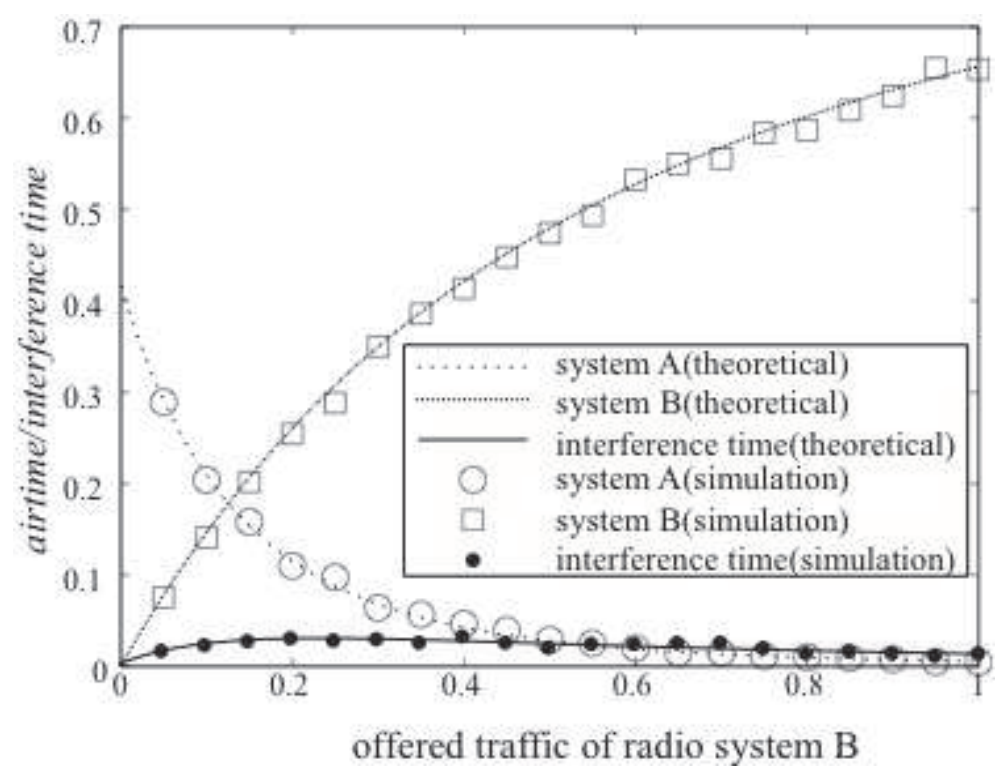

Fig. 2. Airtime of each system and interference time vs. offered traffic of radio system B. 


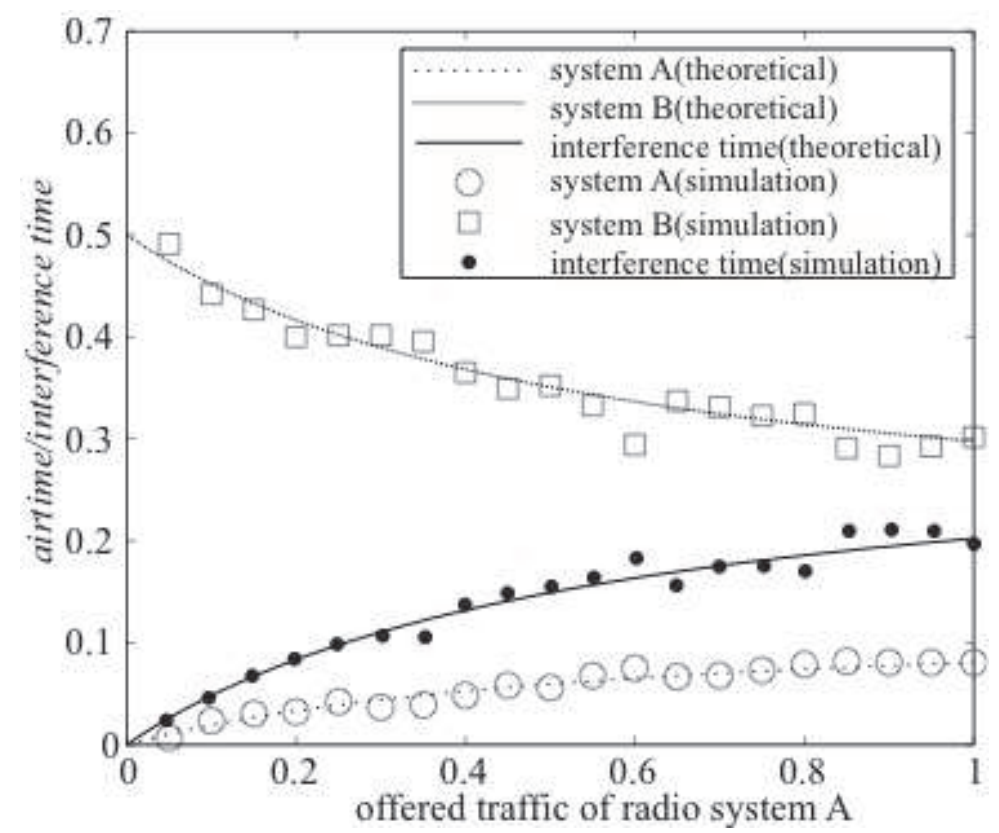

Fig. 3. Airtime of each system and interference time vs. offered traffic of radio system A.

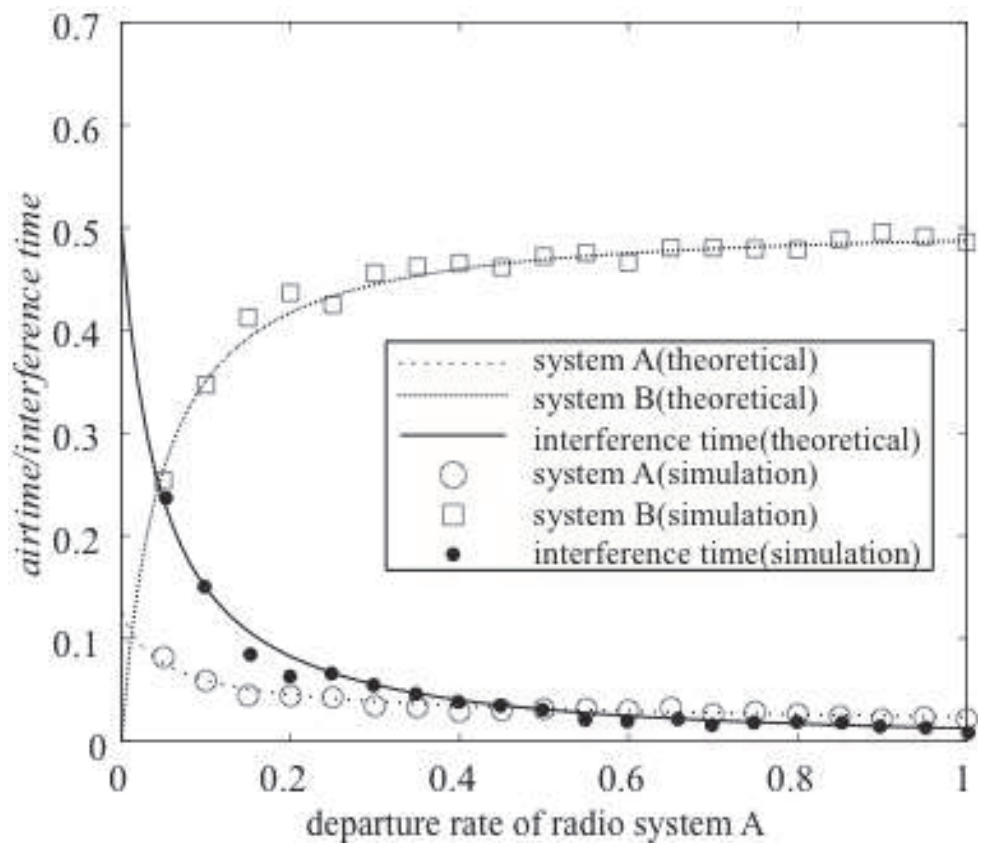

Fig. 4. Airtime of each system and interference time vs. departure rate of radio system A. 


\section{The performance analysis of UWB radio system with DAA}

In Section 3, we show that the mutual interference is inherently occurred even with the ideal cognitive radio technology. However, in practical situations, the cognitive radio technologies cannot detect the primary systems ideally and this effect may degrade the performance of the primary systems. Therefore, in this section, the performance of the interference mitigation technique for UWB radio communications is investigated under a practical scenario. Detection technique of primary system for UWB system is discussed and also the avoidance technique of interference to primary system for UWB system is presented [5].

\subsection{Detection technique primary system}

We consider coexistence environment between UWB system and primary system such as $4 \mathrm{G}$ and WiMAX under the indoor environment. The detection scheme of primary system signal using MB-OFDM receiver is studied in order to realize DAA operation. By comparing the estimated average power of primary system signal obtained from the fast fourie transform (FFT) outputs corresponding to the primary band with the background noise average power, detection is performed. For the comparison, it is necessary to determine the appropriate threshold value so that the miss-detection probability can be made smaller. In order to perform value for detection this, theoretical detection and missdetection probabilities are obtained and they are used to determine the threshold value for detection.

The MB-OFDM system has $N$ sub-carriers and the continuous $M$ sub-carriers are interfered from the primary system signals within the limits of the band of primary system. Therefore, $N$ sub-carriers the observation signal of MB-OFDM receiver is represented as component interference and component noise.

If the average power of $N$ sub-carriers is larger than the average power of $(N--M)$ subcarriers, then the detector assumes that the primary system exists.

\subsection{Avoidance technique of interference for primary system}

Among the interference avoidance techniques to primary systems, active interference cancellation (AIC) is the simplest one in the frequency domain. In this technique the MBOFDM receiver detects the primary system signals and the part of sub-carriers which overlaps the frequency band of primary system are not transmitted therefore forming a notch. Moreover, this technique reduces the effect of side lobe from neighbor sub-carriers. Therefore, in this paper, we assume MB-OFDM system can avoid the interference to primary system by using arbitrary avoidance techniques. Therefore, we consider the performance of MB-OFDM system with interference mitigation technique for primary systems. Also, we show significant performance improvement by introducing convolutional codes with bitwise interleaving.

\subsection{Numerical results}

\subsubsection{Analysis of detection technique}

The detection and miss-detection probabilities of primary system in MB-OFDM receiver is shown in Fig. 5. 
The detection probability depends on signal to noise ratio (SNR) and threshold, and the miss-detection probability depends on only the threshold. Here, SNR is defined the MBOFDM signal to noise ratio. Although the low threshold should be chosen to obtain the high detection probabilities, the low threshold also increase the miss-detection probabilities. Hence, the threshold value should be changed dynamically according to the SNR to keep the constant detection probability. Fig. 6 indicates the relationship between threshold and SNR which is satisfied the arbitrary detection probability such as $60,70,90 \%$. The missdetection probability of the dynamic threshold is shown in Fig. 7.

In Fig. 6, a constant detection probability is obtained since threshold is dynamically changed by following SNR. The high threshold is required to obtain the high data rate. However, the high threshold inherently increase the miss-detection probability and thus the throughput of the MB-OFDM system is decreased.

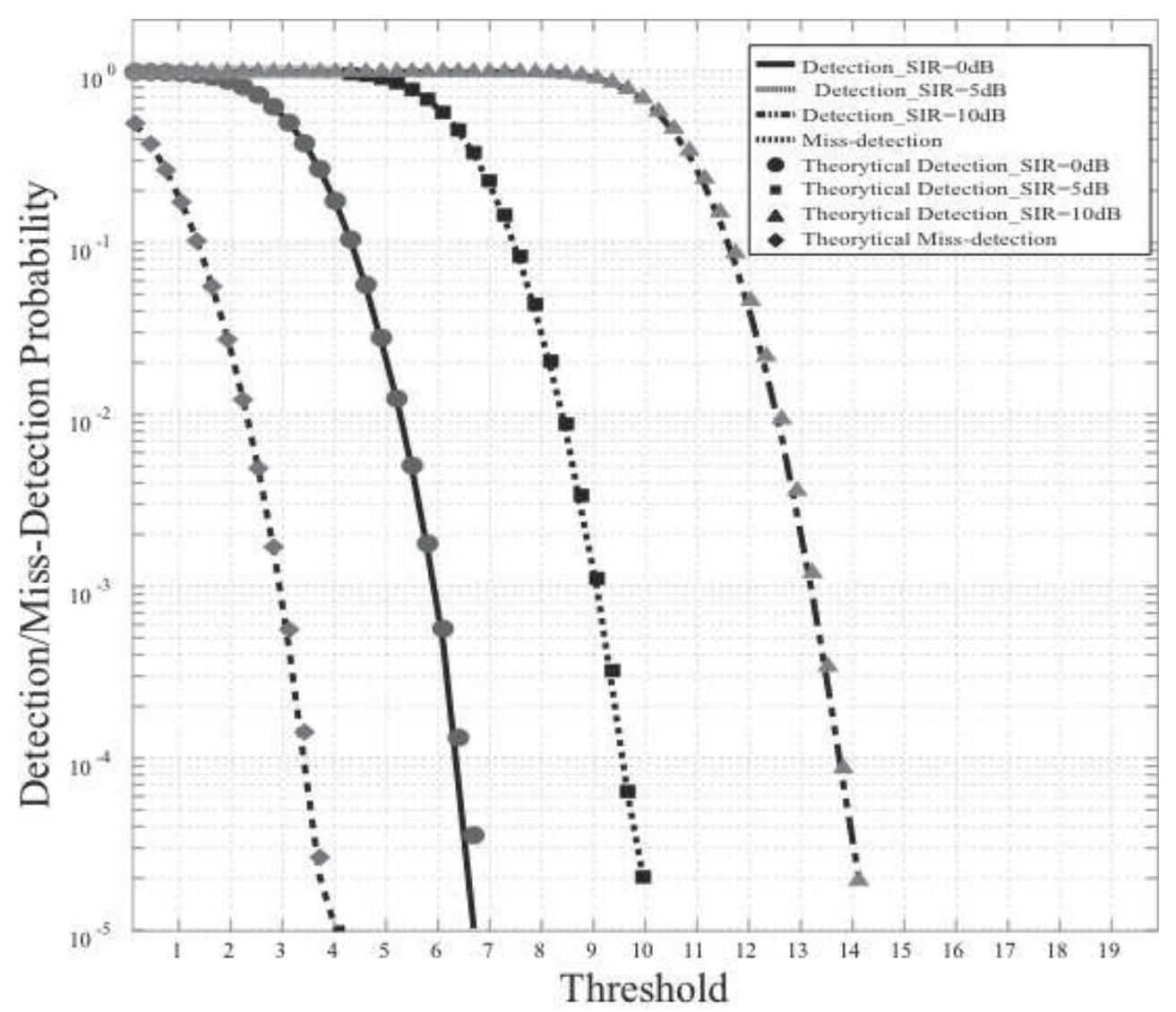

Fig. 5. The detection/miss-detection probability of primary system 


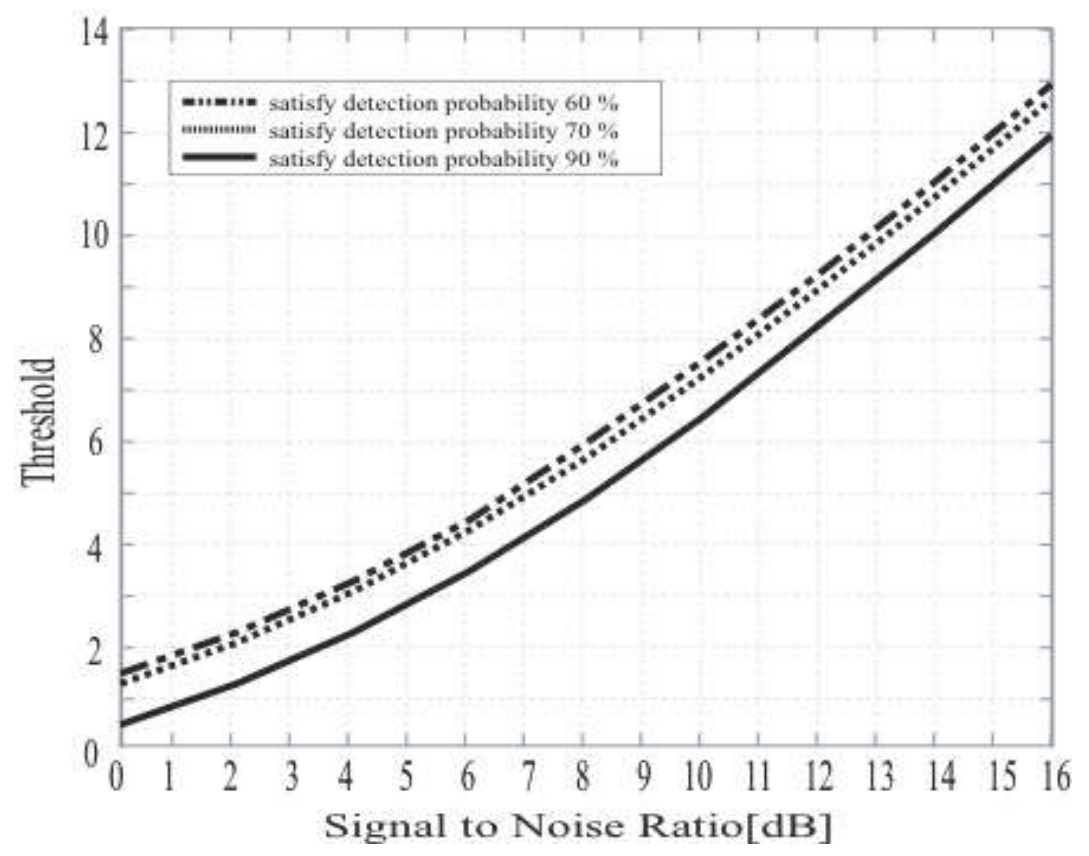

Fig. 6. The relationship between threshold and SNR which is satisfied the arbitrary detection probability

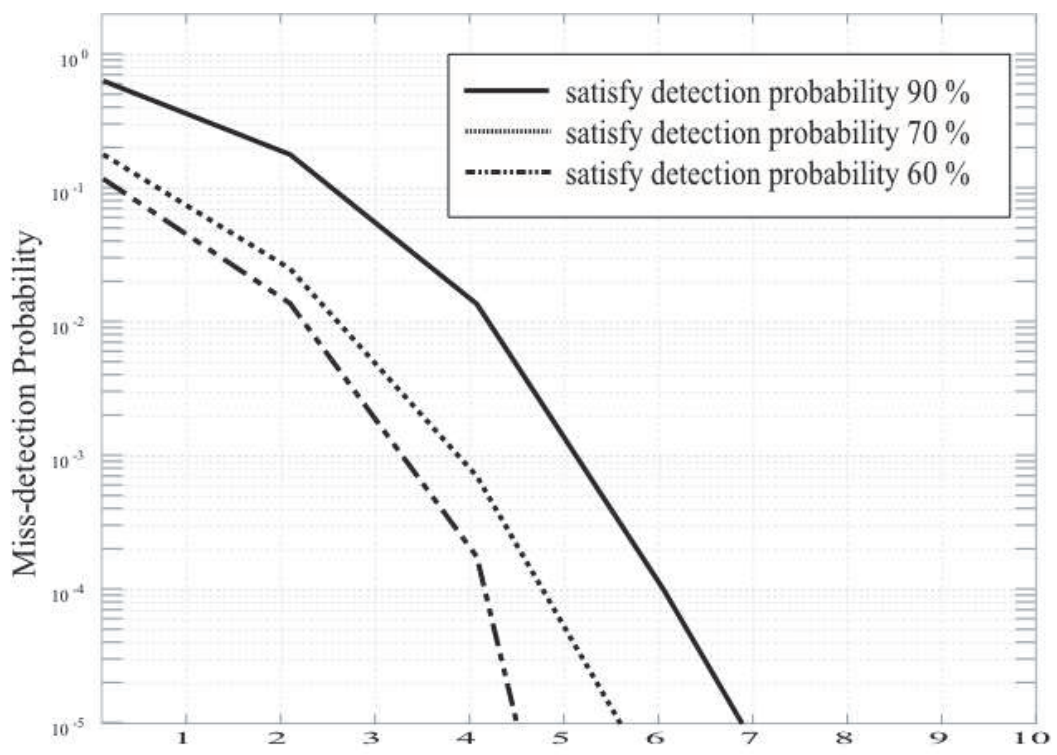

Signal to Noise Ratio [dB]

Fig. 7. The miss-detection probability of dynamic threshold following SNR 


\subsubsection{Analysis of interference avoidance technique}

The BER of MB-OFDM system with error correction code and interleave is illustrated in Fig. 8 .

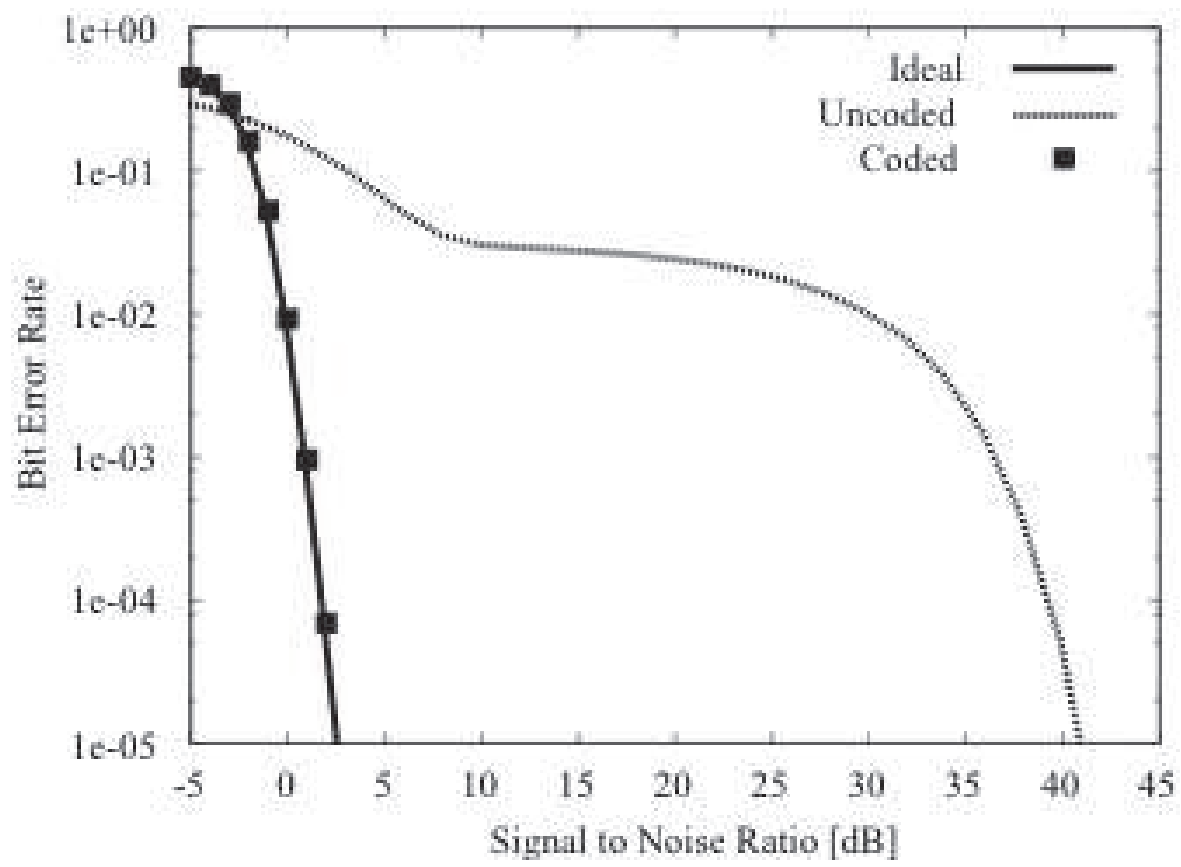

Fig. 8. The performance of MB-OFDM system with DAA

In Fig. 8, the device with DAA technique has a high bit error rate (BER). The error floor observed in moderate SNR region is due to the power control, which makes the transmission power level as $-70 \mathrm{~dB} / \mathrm{MHz}$ in the band overlapping with the primary system. The BER is decreased exponentially again in the high SNR region more than $35 \mathrm{~dB}$. Moreover, combining the bit-interleaved convolution code with DAA, the performance of MB-OFDM system can be further improved and is asymptotically identical with the ideal performance.

\section{Conclusion}

In this chapter, we studied dynamic spectrum access technology in the coexistence environment of primary systems and cognitive radio systems. We can conclude that the occupancy time of channels should be shortened for cognitive radio systems rather than decreasing offered traffic (i.e., arrival rate) since the departure rate is inverse proportion to the occupancy time.

Moreover, we showed the performance of UWB radio system with DAA in the coexistence environment between UWB systems and primary systems. DAA technique should be chosen in consideration to the required performance quality of UWB applications. The realtime applications such as verbal communication and high-quality video across the 
wireless communication are essential to high data rate. Therefore, the unused frequency band by the primary systems needs to allocated. In this case, the detector of UWB needs a high detection probability. On the other hand, in the application that allows time delay, transmitter power control to avoid the interference to primary systems is applied. Interestingly, the BER performance of bit-interleaved convolutional coded MB-OFDM with the transmit power control is almost identical with the ideal performance. Hence, this fact leads that the miss-detection of the primary system may not affect the performance of the UWB systems. Thus, DAA technology is the effective interference mitigation techniques of high data rate UWB system.

\section{Acknowledgment}

This work is partly supported by Research Fellowships of the Japan Society for Promotion of Science.

\section{References}

[1] A. Batra, "Time Multi-Band OFDM Physical Layer Proposal for IEEE 802.15 Task Group 3a," IEEE P802.15-04/493r1-TG3a, Sep. 2004.

[2] FCC, ET Docket No 03-222 Notice of proposed rule making and order, Dec. 2003.

[3] Functional Requirements for the 802.22 WRAN Standard IEEE.

[4] John Polson, "Cognitive Radio Applications in software Defined Radio," Software Defined Radio Technical Conference, Phoenic, Arizona, Nov. 2004.

[5] K. Sodeyama, M. Itami, R. Kohno, "Performance Analysis of Interference Mitigation Method for 4G Cellular Systems with MB-OFDM UWB Systems", The 29th Symposium on Information Theory and Its Applications, Nov. 2006.

[6] K. Watanabe, K. Ishibashi, R. Kohno, "An Analysis of Spectrum Management for Coexistence of Fixed and Cognitive Radio Systems," 2006 Software Defined Radio Technical Conference, Nov. 2006.

[7] M. Z. Win, R. A. scholtz, "Ultra-Wide Bandwidth Time-Hopping Spread-Spectrum Impulse Radio for Wireless Multiple-Access Communications," IEEE Trans. Commun., vol. 48, no. 4, pp. 679?691, April 2000.

[8] Q. Zhao. B. Sadler, A Survey of Dynamic Spectrum Access," IEEE Signal Processing Mag., vol. 24, no. 3, pp. 79-89, May 2007.

[9] S. Haykin, "Cognitive Radio: Brain-Empowered Wireless Communications," IEEE J-SAC, vol. 23, no. 2, pp. 201-220, Feb. 2005.

[10] S. Mangold, K. Challapali, “Coexistence of Wireless Networks in Unlicensed Frequency Bands," WWWRF\#9 meeting, Jul. 2003.

[11] T. Zasowski, A. Wittneben, "Performance of UWB Systems using a Temporal Detectand-Avoid Mechanism," The International Conference on Ultra-Wideband, Sep. 2006.

[12] V. S. Somayazulu, J. R. Foerster, R. D. Roberts, "Detect and Avoid (DAA) Me chanisms for UWB Interference Mitigation," The International Conference on Ultra-Wideband, Sep. 2006. 


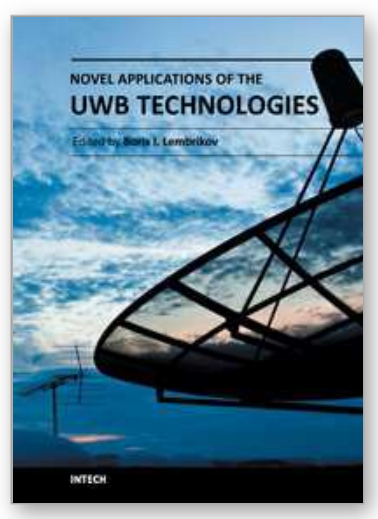

\author{
Novel Applications of the UWB Technologies \\ Edited by Dr. Boris Lembrikov
}

ISBN 978-953-307-324-8

Hard cover, 440 pages

Publisher InTech

Published online 01, August, 2011

Published in print edition August, 2011

Ultra wideband (UWB) communication systems are characterized by high data rates, low cost, multipath immunity, and low power transmission. In 2002, the Federal Communication Commission (FCC) legalized low power UWB emission between $3.1 \mathrm{GHz}$ and $10.6 \mathrm{GHz}$ for indoor communication devices stimulating rapid development of UWB technologies and applications. The proposed book Novel Applications of the UWB Technologies consists of 5 parts and 20 chapters concerning the general problems of UWB communication systems, and novel UWB applications in personal area networks (PANs), medicine, radars and localization systems. The book will be interesting for engineers and researchers occupied in the field of UWB technology.

\title{
How to reference
}

In order to correctly reference this scholarly work, feel free to copy and paste the following:

Keisuke Sodeyama and Ryuji Kohno (2011). Performance Analysis of Spectrum Management Technique by Using Cognitive Radio, Novel Applications of the UWB Technologies, Dr. Boris Lembrikov (Ed.), ISBN: 978953-307-324-8, InTech, Available from: http://www.intechopen.com/books/novel-applications-of-the-uwbtechnologies/performance-analysis-of-spectrum-management-technique-by-using-cognitive-radio

\section{INTECH}

open science | open minds

\section{InTech Europe}

University Campus STeP Ri Slavka Krautzeka 83/A 51000 Rijeka, Croatia Phone: +385 (51) 770447 Fax: +385 (51) 686166 www.intechopen.com

\section{InTech China}

Unit 405, Office Block, Hotel Equatorial Shanghai No.65, Yan An Road (West), Shanghai, 200040, China 中国上海市延安西路65号上海国际贵都大饭店办公楼405单元 Phone: +86-21-62489820

Fax: +86-21-62489821 
(C) 2011 The Author(s). Licensee IntechOpen. This chapter is distributed under the terms of the Creative Commons Attribution-NonCommercialShareAlike-3.0 License, which permits use, distribution and reproduction for non-commercial purposes, provided the original is properly cited and derivative works building on this content are distributed under the same license. 